\section{Loss of resistance technique for locating the epidural space: evaluation of glass and plastic syringes}

Bruce D. Butler PhD, Robert D. Warters BME, J. Rael Elk MB ChB, Ian Davies MB BCh, Ezzat Abouleish MD
Location of the epidural space in epidural anaesthesia usually involves the measurement of loss of resistance using glass or plastic syringes. In the present study two varieties of glass syringe and one plastic type were evaluated to determine the resistive forces associated with plunger movement. The mean static $(f s)$ and dynamic (fd) forces for polished glass syringes having a ground plunger only were $f s=0.47 \times 10^{-3} \pm 0.22 \times$ $10^{-3} \mathrm{~N}$ and $f d=0.37 \times 10^{-3} \pm 0.19 \times 10^{-3} \mathrm{~N}$ and for polished glass syringes having a ground barrel and plunger were $f s=$ $0.43 \times 10^{-3} \pm 0.16 \times 10^{-3} \mathrm{~N}$ and $f d=0.38 \times 10^{-3} \pm 0.15 \times$ $10^{-3} \mathrm{~N}$. Each of these values was significantly lower $(P<0.5)$ than those for plastic syringes $f s=2.22 \times 10^{-3} \pm 0.48 \times 10^{-3}$ $\mathrm{N}$ and $\mathrm{fd}=1.46 \times 10^{-3} \pm 0.37 \times 10^{-3} \mathrm{~N}$. It is concluded that glass syringes are favoured over plastic for locating the epidural space because frictional forces developed with glass syringes were significantly lower than with plastic.

Afin de trouver l'espace épidural on a recours habituellement à la perte de résistance dans les seringues de verre ou de plastique. Dans celte étude, on a évalué deux variétés de seringues de verre et un type de seringue en plastique, afin de déterminer les forces de résistance associées au mouvement $d u$ piston. Les forces moyennes statiques ( $f$ s) et dynamiques (fd) pour les seringues de verre poli ayant un plongeur dépoli érair de $f_{s}=0.47 \times 10^{-3} \pm 0,22 \times 10^{-3} \mathrm{Net} f d=0,37 \times 10^{-3} \pm 0,19$ $\times 10^{-3} \mathrm{~N}$ alors que pour les seringues de verre poli ayant un barillet et un piston dépoli était de $f s=0,43 \times 10^{-3} \pm 0.16 \pm$ $10^{-3} \mathrm{~N}$ ef $\mathrm{fd}=0,38 \times 10^{-3} \pm 0,15 \times 10^{-3} \mathrm{~N}$. Chacune de ces

\section{Key words}

ANAESTHETIC TECHNIQUES: epidural; EQUIPMENT: syringes, plastic and glass.

From the Department of Anesthesiology, The University of Texas Medical School at Houston.

Address correspondence 1o: Dr. B.D. Butler, Department of Anesthesiology, The University of Texas Medical School at Houston, 6431 Fannin, 5.020 MSMB, Houston, Texas 77030 U.S.A. valeurs étaient significativement plus basses $(P<0.05)$ de celles des seringues en plastiques $f s=2,22 \times 10^{-3} \pm 0,48 \times 10^{-3} \mathrm{~N}$ et $f d=1,46 \times 10^{-3} \pm 0,37 \times 10^{-3} \mathrm{~N}$. On conclut que les seringues de verre som meilleures que celles en plastique pour localiser l'espace épidural.

Accurate location of the epidural space for epidural anaesthesia relies upon the sensitivity of the technique and material used in the hands of a skilled physician. Classical methods for locating the epidural space utilize liquid- or air-filled syringes and the loss of resistance to forward plunger movement to determine the point at which the needle penetrates the ligamentum flavum. The quality of the syringe can be considered an important factor in the rate of success in using the loss of resistance technique. Ideally the resistance to plunger movement should either be minimal or at least impart minimal inconsistencies in barrel motion. Glass syringes are occasionally associated with jamming or sticking ${ }^{1}$ and hence the advocacy of barrel lubrication by wetting with saline or other suitable liquid is commonly reported. ${ }^{2}$ Previous investigations have established that minimal resistance to glass syringe barrel motion occurs by dry polishing procedures. ${ }^{3}$ The purpose of this study was to evaluate further the resistance to plunger motion using two types of glass syringe and one type of dedicated purpose plastic syringe. ${ }^{4}$

\section{Methods}

The procedures for measuring the resistance to plunger movement in a syringe barrel have been previously reported. ${ }^{3}$ Three manufacturers' syringes that are used for epidural anaesthesia were evaluated. One brand of glass syringe had a ground barrel ( $5 \mathrm{ml}$, B-D Yale; Pharmaseal, $n=9)$, another had both ground barrel and plunger $(5 \mathrm{ml}$, Deseret, $n=9$ ) and the third was plastic ( $7 \mathrm{ml}$, Pulsator; Concord, $n=10$ ), specifically designed for epidural use with loss of resistance technique. Each of the glass syringes was dry polished. This procedure consisted of rotating the barrel within the plunger for five complete revolutions in each direction, for a total of ten revolutions. 
TABLE Measured force, static (fs) and dynamic (fd)

\begin{tabular}{llll}
\hline & Ground glass plunger & Ground glass plungeribarrel & Plastic \\
\hline fs (N) & $0.47 \times 10^{-3} \pm 0.22 \times 10^{-3}$ & $0.43 \times 10^{-3} \pm 0.16 \times 10^{-3}$ & $2.22 \times 10^{-3 *} \pm 0.48 \times 10^{-3}$ \\
fd (N) & $0.37 \times 10^{-3} \pm 0.19 \times 10^{-3}$ & $0.38 \times 10^{-3} \pm 0.15 \times 10^{-3}$ & $1.46 \times 10^{-3 *} \pm 0.37 \times 10^{-3}$ \\
\hline
\end{tabular}

Mean $\pm \mathrm{SD}$

* $P<0.0005$ compared with ground glass plunger or ground glass plunger/barrel.

$\mathrm{N}=$ Newton

Preliminary studies indicated that additional polishing had no effect on resistance to movement. The plastic syringe barrels were maximally withdrawn and reinserted several times before measurements were taken.

The experimental procedure consisted of mounting the barrel of each syringe in the horizontal position on a motorized slide (Uniglide, Velmex) with the plunger inserted. The syringe barrel was connected to a force transducer (Grass IOD) by nonelastic thread. The plunger was then withdrawn from the barrel at a rate of 6.5 $\mathrm{cm} \cdot \mathrm{sec}^{-1}$ while constantly recording from the force transducer on a chart recorder (Gould). Each syringe was tested twice. The data were recorded as the static force ( $f s$ ) of resistance, occurring the instant movement began, and as dynamic force of resistance ( $\mathrm{fd}$ ) once a steady-state was achieved on the recording. All data were collected at room temperature. Data were analyzed using ANOVA. Individual comparisons were made using Bonferroni t tests.

\section{Results}

The $f s$ and fd data are presented in the Table. The $f s$ and $f d$ data from the two types of glass syringes were not significantly different from each other. The plastic syringes had fs and fd values significantly greater than either of the glass syringe groups. Variability, as determined by the standard deviation of the respective mean for each group, was greater with the glass than with the plastic syringes.

\section{Discussion}

Although a number of techniques is available for locating the epidural space, either for injection or cannulation, one of the more commonly used involves loss of resistance to the injection of a column of fluid consisting of air or sterile solution. Traditionally, glass syringes have been utilized for this purpose. In an effort to enhance lubrication of the barrel/plunger interface, Bromage ${ }^{2}$ suggested wetting the two components. Leiman et al. ${ }^{3}$ have indicated, however, that wetting with saline results in fs values of $2.75 \times$ $10^{-3} \pm 0.69 \times 10^{-3} \mathrm{~N}$ and fd values of $1.95 \times 10^{-3} \pm$ $0.41 \pm 10^{-3} \mathrm{~N} .{ }^{4}$ These values are significantly greater than the dry polished values reported in the Table, yet more closely resemble the values obtained for the plastic syringes (fs $=2.25 \times 10^{-3} \pm 0.43 \times 10^{-3} \mathrm{~N}$ and fd $\left.=1.46 \times 10^{-3} \pm 0.38 \times 10^{-3} \mathrm{~N}\right)$.

Increasingly plastic syringes are being used in conjunc- tion with the loss of resistance technique to locate the epidural space. In the present study, plastic syringes were compared with two types of glass syringe, one with one ground surface and another with two ground surfaces. Having a ground glass plunger only, versus a ground glass plunger and barrel did not significantly affect resistance to movement. The resistance with the plastic syringes was significantly higher than with either glass syringe. Sticking or jamming of the plunger in the barrel did not occur with any of the plastic syringes, but did with both types of glass syringes with an 11 per cent incidence. The variability between individual syringes was greater with the glass syringes than the plastic ones.

The present study involved the withdrawal of the syringe plunger from the barrel in a controlled fashion. The net resistive forces are equal in either direction of movement, attesting to the validity of the measurement. Although sticking or jamming is more likely to occur with forward motion of the plunger, the present study was intended to measure forces relating to friction. It is intended that this study will provide additional data to support clinical choice, in that it quantitated frictional forces which are primary determining factors in the loss of resistance technique for locating the epidural space. The authors prefer the use of glass syringes for this technique because of the reduced amount of friction. However, the final preference of any individual anaesthetist is based upon personal experience which determines the particular type of equipment used, including syringes.

\section{Acknowledgment}

The authors thank Mrs. Verna Jasso for typing this manuscript.

\section{References}

1 Doughty A. A precise method of cannulating the lumbar epidural space. Anaesthesia 1974; 29: 63.

2 Bromage PR. Epidural Anaesthesia. Philadelphia: W.B Saunders, 1978: 195.

3 Leiman BC, Katz J, Salzarulo H, Warters HD, Buller $B D$. A comparison of different methods of lubrication of glass syringes used to identify the epidural space.

Anaesthesia 1988; 43: 397.

4 Manchikanti L. Epidural syringes. Anaesthesia 1988; 43: 1066. 